\title{
O Afluxo de refugiados e "deslocados de guerra" para as minas de carvão do Rio Grande do Sul ao fim da II Guerra
}

\section{The Flow of Refugees and Displaced Persons to the Coal Mines of Rio Grande do Sul After the II World War}

\section{Clarice Gontarski SPERANZA*}

Resumo As vilas mineradoras de Arroio dos Ratos e Butiá, no Rio Grande do Sul, eram, na primeira metade do século XX, uma das maiores concentrações de trabalhadores do sul do Brasil. Com cerca de 7 mil operários concentrados, a região foi líder na produção brasileira de carvão mineral até o fim da II Guerra Mundial. Ao final do conflito, mesmo com a queda da demanda pelo produto, houve um grande incentivo à imigração de refugiados europeus, em especial russos, poloneses, alemães, ucranianos e outros. Tal contexto gerou um aumento na concentração de nacionalidades e etnias nas vilas, bem com um incremento nos mecanismos de controle da mão de obra, incluindo a classificação dos trabalhadores em "bons", "regulares" e "maus" pelas grandes empresas mineradoras. A partir da documentação empresarial até então inédita, este estudo analisa o processo de "importação" dos trabalhadores via instrumentos diplomáticos e governamentais e as

\footnotetext{
* https://orcid.org/0000-0002-9795-7823

Universidade Federal do Rio Grande do Sul, Departamento de História Av. Bento Gonçalves, 9500, 90040-060, Porto Alegre, RS, Brasil clarice.speranza@gmail.com
} 
estratégias de comando patronais, bem como experiências de resistência e de adaptação dos operários ao cotidiano extremamente insalubre das minas de carvão.

Palavras-Chave trabalho, imigração, mineiros de carvão

Abstract The mining villages of Arroio dos Ratos and Butiá, in Rio Grande do Sul, were, in the first half of the 20th century, two of the largest concentrations of workers in the south of Brazil. With a concentration of around 7,000 workers, the region was a leader in Brazilian coal production until the end of World War II. At the end of the conflict, even with the decrease of the product's demand, there was great incentive to the immigration of European refugees, especially Russians, Poles, Germans, Ukrainians and others. Such context increased the concentration of nationalities and ethnicities in the villages, as well in the mechanisms for controlling the workforce, including the classification of workers as "good", "regular" and "bad" by large mining companies. Based on previously unpublished business documentation, this study analyzes the process of "importing" workers via diplomatic and government instruments and employers' command strategies, as well as experiences of resistance and adaptation of workers to the extremely unhealthy environment of coal mines.

KEYWORDS labor, immigration, coalminers

Ao fim da II Guerra Mundial, a Europa vivia um problema social significativo, com grandes contingentes populacionais miseráveis, deslocados ou não de suas regiões de origem durante o conflito. Eram em torno de um milhão de pessoas, sendo que dessas cerca de 638 mil (a maioria poloneses), estavam nas zonas de ocupação estadunidense, francesa e britânica (SALLES, 2002, p. 100-101; BRAVO, 2014, p. 14-15). Para esses, a recém-criada ONU exibia como alternativas a repatriação, a manutenção em campos de refugiados, a entrega das populações para Áustria e Alemanha, e a migração para outras terras. A entidade criou um órgão especial para enfrentar o problema, a Organização Internacional 
de Refugiados (OIR), e promoveu acordos com diversos países para receber os refugiados e os "deslocados de guerra".

O Brasil foi dos primeiros países a manifestar interesse em abrigar esses trabalhadores. Salles (2002) argumenta que o imediato pós-guerra pode ser caracterizado como o quarto momento de grande afluxo de imigrantes para o Brasil (sem considerar a migração forçada africana decorrente da escravidão negra). Caracteriza-se por um afrouxamento das restrições, tendo um fluxo bem menor que os períodos anteriores, em especial entre fins do século XIX e início do XX - momento no qual a migração, predominantemente europeia, foi marcada pela demanda gerada pela expansão cafeeira e por subsídios estatais ou privados, tendo como principais objetivos a substituição da mão de obra escravizada, o "branqueamento" da população e a colonização de territórios até então ocupados por povos indígenas.

Após a II Guerra Mundial, pelo contrário, esses três objetivos já tinham perdido sua força - apesar de a ideologia do "branqueamento" continuar povoando os projetos de nação da elite branca, porém agora ressignificada pelo "mito da democracia racial" de Gilberto Freyre. Os interesses que envolveram a vinda de imigrantes europeus no pós-guerra estavam mais ligados à demanda por mão de obra especializada e barata. "O bom imigrante continuava sendo o agricultor, mas aparecia

1 Embora muitas vezes tratadas como sinônimos na documentação (e aparentemente na prática, ao menos no Brasil), as duas categorias pelas quais a ONU classificava, em 1946, as numerosas populações desterradas na Europa eram em tese vistas como bastante diversas. O termo "refugiado" se aplicava a uma pessoa que estava fora de seu país natal ou de residência e que, tendo ou não mantido sua nacionalidade, pertencesse a um dos seguintes casos: vítimas dos regimes nazistas ou fascistas; republicanos espanhóis e outras vítimas do regime do ditador Francisco Franco; pessoas que eram consideradas refugiadas antes da eclosão da guerra por razões de raça, religião, nacionalidade ou opinião política. Também eram considerados refugiados os grupos judeus vítimas da perseguição nazista, além de crianças e jovens com menos de 16 anos cujos pais tivessem morrido ou desaparecido no conflito. Já entre os "deslocados de guerra" (displaced persons) incluíam-se pessoas deportadas ou obrigadas a deixar seu país natal ou de residência, incluindo populações obrigadas a realizar trabalhos forçados ou que haviam sido deportadas por razões raciais, religiosas ou políticas. As soluções preconizadas para os dois grupos eram também diferentes. UN General Assembly. Refugees and Displaced Persons, 15 Dec. 1946, A/RES/62. Disponível em: <https://www.refworld.org/docid/3b00f1963c.html> Acesso em: 05 jan. 2021. 
claramente a necessidade do novo, do técnico, do indivíduo qualificado para o trabalho industrial" (BASTOS; SALLES, 2014, p. 155).

Outros autores salientam razões diplomáticas para a adesão do Brasil ao esforço de acolhimento dos refugiados e deslocados do conflito. Andrade (2005) e Bravo (2014) mencionam, por exemplo, o alinhamento aos Estados Unidos do governo de Eurico Gaspar Dutra e a busca por prestígio no xadrez internacional, incluindo assento no Conselho Geral da OIR. Por outro lado, o país teria deixado claro desde o início que buscava um tipo específico de mão de obra: "técnicos e agricultores; que estivessem aptos a povoar áreas inóspitas do território nacional e que contribuíssem para o reforço das características europeias ancestrais do povo brasileiro" (BRAVO, 2014, p. 72).

Os "deslocados", em especial, eram considerados como fonte de mão de obra qualificada para a então florescente indústria nacional. Conforme Salles (2007, p. 202), as profissões mais requisitadas pelos industriais brasileiros eram mecânicos de todos os níveis de especialização para montagem, reparação e manutenção de motores e máquinas; especialistas em fiação e tecelagem; técnicos em indústrias químicas; operários para metalúrgicas e para extração de carvão.

Nossa hipótese neste artigo $^{2}$ é que, a despeito ou em paralelo ao objetivo governamental e diplomático, a importação de mão de obra também foi uma estratégia utilizada por empresários para confrontar o crescentemente organizado movimento operário, que apesar da repressão da ditadura do Estado Novo, ressurgiu com força já em 1945 com greves e com a campanha do "queremismo". ${ }^{3}$ A retomada da mobilização foi marcada também pelo aumento da sindicalização - havia 474.943 trabalhadores filiados a sindicatos em 1945 e, no ano seguinte, esse número já havia crescido para 797.691 - e pela criação de centrais como o

2 Uma versão preliminar deste trabalho foi apresentada na Décima Reunión Anual y Encuentro Académico Internacional del Comité Académico de Historia, Regiones y Fronteras (CHRyF) de la Asociación de Universidades del Grupo Montevideo (AUGM), em Valparaíso, no Chile, em abril de 2019.

3 Para uma síntese da campanha do queremismo, ver FERREIRA, 2003; FRENCH, 1995. 
Movimento Unificado de Trabalhadores (MUT) em 1945, e a Confederação dos Trabalhadores do Brasil (CTB), em 1946 (MATTOS, 2009). Tal esforço de organização se refletiu no número de greves, que alcançaram 77 paralisações somente nos dois primeiros meses de 1946 (GOMES, 2007), incluindo categorias significativas como bancários, gráficos e ferroviários.

Nesse sentido, investigamos um dos setores que mais buscou atrair os refugiados e os "deslocados de guerra”: a mineração de carvão, em especial as empresas do extremo sul do país, no Rio Grande do Sul. Esse setor também foi marcado por uma intensa mobilização operária. Os mineiros de carvão protagonizaram greves massivas em 1945 e 1946, que motivaram inclusive a ocupação militar nas vilas mineiras e a demissão de centenas de operárias (KONRAD, 2006; SPERANZA, 2014).

A exploração do carvão mineral no Rio Grande do Sul estava concentrada nas mãos de grandes empresas, em especial duas, a Companhia Estrada de Ferro e Minas de São Jerônimo (CEFMSJ) e a Companhia Carbonífera Minas do Butiá (CCMB), que haviam se unido em um Consórcio Administrativo, o Cadem, em 1936. Desde o final do século XIX, o modelo de produção implantado nessas indústrias incluiu a atração constante de novos trabalhadores, do exterior ou de outras regiões do Brasil, em paralelo ao aliciamento da população rural ou de trabalhadores de outros estados. Os operários das minas sofriam com péssimas condições de trabalho e índices alarmantes de problemas de saúde, em especial doenças pulmonares. ${ }^{4}$

A migração de trabalhadores de outras partes do Rio Grande do Sul, de outros estados e de outros países era constante, o que aparece referido na documentação das empresas. Ofícios endereçados pela direção das minas, no Rio Grande do Sul, à administração central da CEFMSJ, ${ }^{5}$

4 Em 1943, o sindicato local encaminhou um dissídio coletivo à Justiça do Trabalho, denunciando uma série de irregularidades nas minas e no pagamento dos trabalhadores. O dissídio acabou sustado por uma portaria do Ministério do Trabalho, sob justificativa da II Guerra Mundial (DISSÍDIO COLETIVO, 1943).

5 ARQUiVO DOCUMENTAL DO MUSEU ESTADUAL DO CARVÃO (ADMEC), Arroio dos Ratos. Acervo Companhia Estrada de Ferro e Minas de São Jerônimo (CEFMSJ), Fundo Administração, Cartas 1933-1934, 15 jul. 1933. Cx. 1, f. 203. 
no Rio de Janeiro, em 1933, por exemplo, dão conta do envio tanto de operários de outros estados, como Minas Gerais, como também de estrangeiros, que nem sempre apreciavam ou mesmo aceitavam as condições de trabalho com as quais se defrontavam. Em agosto daquele ano, por exemplo, dezenas de trabalhadores alemães, austríacos e espanhóis, ${ }^{6}$ entre outras nacionalidades, enviados do Rio de Janeiro, recusaram-se a trabalhar e foram mandados de volta. Muitos eram padeiros, alfaiates e vendedores ambulantes, sem experiência no duro trabalho de extração do carvão. A carta da direção das minas reclamando à administração carioca dá pistas sobre o processo de aliciamento dos imigrantes com promessas depois não cumpridas:

Os operários que chegaram pelo vapor Itanagé são homens das mais diversas profissões, que desconhecem por completo o que se entende por tocador ou furador. Entre eles somente existiam dois com conhecimento do serviço das minas, os quais porém desejavam um ordenado mínimo de $17 \$ 000$ como tocadores, pretensão essa que não nos é possível atender. Entre eles existia um regular número de alemães e austríacos que alegavam terem sido iludidos aí no Rio com promessas de ordenados elevados, tendo feito exigências descabidas por ocasião de sua chegada aqui. (...) O Chefe da Mineração havia pedido elementos daí por necessitar de gente prática, pois aqui pode-se encontrar facilmente trabalhadores, porém, sem serem especialistas. ${ }^{7}$

6 Há indícios de um número significativo de espanhóis sendo admitidos nos anos 1920, alguns tendo anteriormente passado pela Mina de Morro Velho, em Minas Gerais. A relação de integrantes da colônia espanhola em Morro Velho (MG) e as minas de carvão do Rio Grande do Sul aparecem também em relatos orais, documentos policiais e livros de memória. Sobre o afluxo de trabalhadores espanhóis em Morro Velho no fim do século XIX e início do XX, ver SOUZA, 2009.

7 ADMEC, Arroio dos Ratos. Acervo CEFMSJ, Fundo Administração, Cartas 1933-1934, 27 jul. 1933. Cx. 1, f. 219-220. 
Em outubro de 1934, um levantamento produzido pela direção da Companhia Estrada de Ferro e Minas de São Jerônimo para a então recém-criada Inspetoria Regional do Trabalho do Rio Grande do Sul indicava a presença de um total de 1.834 trabalhadores nacionais e 307 estrangeiros nas minas de Arroio dos Ratos (em torno de 14\% dos operários), sendo desses 125 espanhóis, 55 poloneses, 20 portugueses, 20 lituanos, 18 alemães, 13 uruguaios, 12 russos, 9 italianos e um número menor de franceses, tcheco-eslovacos, ingleses, romenos, húngaros, austríacos, belgas e outras nacionalidades. ${ }^{8}$ Esse levantamento fora precedido nos meses anteriores pela queixa de um operário brasileiro ao inspetor do trabalho, pedindo a retirada dos chefes estrangeiros da mina, ${ }^{9}$ que ocorria em meio a um contexto de greves e fundação do sindicato, já durante a vigência lei de cotas, que limitava a entrada de imigrantes no Brasil. ${ }^{10}$

Durante o Estado Novo, diante da expansão internacional da demanda pelo carvão provocada pela II Guerra Mundial, o Cadem rio-grandense e diversas mineradoras catarinenses (Barro Branco, Araranguá, Urussanga, Metropolitana, Montanha, Rio Carvão) solicitaram ao Conselho Nacional de Minas e Metalurgia o envio de nordestinos flagelados pelas secas para trabalhar nas minas. ${ }^{11}$

Apesar do incidente de 1933, o fluxo variado de trabalhadores de origens diferentes parece ter evitado a ocorrência de conflitos étnicos mais graves entre os operários das minas de carvão. Não se formaram nas vilas mineiras os chamados "quistos étnicos" característicos dos

8 ADMEC, Arroio dos Ratos. Acervo CEFMSJ, Fundo Administração, Cartas 1934-1935, 31 out. 1934. Cx. 3, f. 106-107.

9 ADMEC, Arroio dos Ratos. Acervo CEFMSJ, Fundo Administração, Cartas 1933-1934, 4 nov. 1933, Cx. 1, f. 340.

10 Sobre esse tema, ver GERALDO, 2009. Quatro anos antes, haviam sido impostos limites ao emprego de trabalhadores estrangeiros. O decreto $\mathrm{n}^{\circ}$ 19.482, de 12 de dezembro de 1930, limitava a entrada, no território nacional, de passageiros estrangeiros de terceira classe, bem como estabelecia a exigência de " $2 / 3$, pelo menos, de brasileiros natos" entre os empregados das empresas.

11 Não conseguimos descobrir se o pedido foi atendido. Sobre a demanda, ver BRASIL. Diário Oficial da União, Rio de Janeiro, 18 jul. 1942, p. 37-38, seção 1. 
núcleos coloniais de predominância absoluta de determinada etnia, em especial italianos ou alemães, no sul do Brasil. Porém, mesmo sem o isolamento e a concentração étnica característica dos núcleos coloniais, as vilas mineiras não passavam ao largo de conflitos envolvendo etnicidade e raça.

A existência de clubes exclusivos para negros nas vilas mineiras (o clube Tesouras, em Arroio dos Ratos; e a Sociedade Ouro Preto, em Butiá), bem como a proibição explícita de que esses trabalhadores frequentassem os clubes "brancos" são um indício de uma sociedade que, apesar da coesão de classe considerada característica do ofício mineiro, era baseada em segregação étnica constante, à semelhança do que foi retratado nas minas de carvão do Alabama por Woodrum (2007). Em entrevista realizada em 2002, um mineiro aposentado, à época com 72 anos, e que havia começado a trabalhar na mina em 1955, relatou: "Os bailes iniciavam as dez, onze horas da noite e iam até às cinco horas da manhã. Ia mais no Clube Tesouras. Era o baile dos negros. Agora deve estar tudo misturado, mas antigamente, não misturava branco com moreno". ${ }^{12}$

Por outro lado, as características monopolísticas e o alto rendimento proporcionado pela exploração do carvão favoreceram a montagem de uma estrutura paternalista de controle nas vilas mineiras (Arroio dos Ratos, Butiá e posteriormente, Charqueadas) relativamente amplo, amparado num sistema vila-fábrica que, ao longo das primeiras décadas do século XX, proveu as comunidades de igreja, delegacia de polícia, hospital, escolas, cinemas, clubes, moradias e urbanização (arruamento, luz elétrica). O auge da produção no Rio Grande do Sul ocorreu durante a II Guerra Mundial, quando a produção alcançou, em 1943, 1,34 milhão de toneladas (65\% da produção brasileira) e a região chegou a empregar cerca de 7 mil operários (SPERANZA, 2014, p. 50-51), que com suas famílias perfaziam uma população estimada em torno de 30 mil pessoas.

12 SOARES, Cerílio Soares, 72 anos. Entrevistador: Ulisses B. dos Santos. Centro de História Oral do Memorial do Rio Grande do Sul, Porto Alegre, 21 jun. 2002. 
Após o fim do conflito, a produção da região foi paulatinamente diminuindo (em detrimento da crescente produção catarinense), porém as grandes empresas de mineração instaladas nas vilas rio-grandenses continuaram sendo um polo importante de atração de imigrantes, em especial refugiados europeus do conflito. Uma série de documentos produzidos no âmbito administrativo das empresas (hoje abrigados no acervo documental do Museu Estadual do Carvão do Rio Grande do Sul) mostra um panorama dessa migração pós-guerra. A partir dessa documentação empresarial, podemos acompanhar os esforços das mineradoras em atrair as populações de trabalhadores vítimas dos dramas sociais resultantes da II Guerra, bem como um dos indícios da resistência dos operários ao processo de trabalho extremamente duro da mineração.

\section{EM BUSCA DE OPERÁRIOS}

Em 1945, o Brasil reabriu a imigração no contexto do final da II Guerra Mundial através do decreto 7.967, porém mantendo a restrição de cotas prevista nos anos 1930. Essa migração se deu em números bem inferiores àquela ocorrida entre fins do século XIX e início do XX, e resultou em boa parte de convênios do governo brasileiro com organismos internacionais responsáveis pelas populações atingidas pelo conflito mundial (BASTOS; SALLES, 2014). Como já mencionamos, os "deslocados de guerra" geralmente possuíam qualificação profissional e haviam sido vítimas de trabalhos forçados nos campos de concentração.

Dados publicados em 1948 pela Revista de Imigração e Colonização mostram que um total de 6.667 "deslocados de guerra" haviam ingressado no Brasil entre 1947 e os nove primeiros meses de 1948, a maioria poloneses (2.492), seguido por ucranianos (1.240), russos (844), iugoslavos (466), lituanos (314), húngaros e austríacos (236 cada), letonianos (229), alemães (207) e outras etnias. ${ }^{13}$ Até 1950, teriam entrado no país 22.009 "deslocados de guerra”, sendo que pouco mais da metade

13 REVISTA de Imigração e Colonização, Rio de Janeiro, v. 9, n. 1, mar. 1948, p. 123. 
dirigida a São Paulo (11.079). O Paraná recebeu o segundo maior número de pessoas (4.606), e o Rio Grande do Sul, o terceiro (2.160), conforme a Revista de Imigração e Colonização (citado por BAENINGER; SALLES, 2013, p. 7-8).

O IBGE, por sua vez, registra um número crescente de imigrantes no país após o conflito mundial, de 1946 a 1952.

Tabela 1. Imigrantes (Brasil), 1940-1960

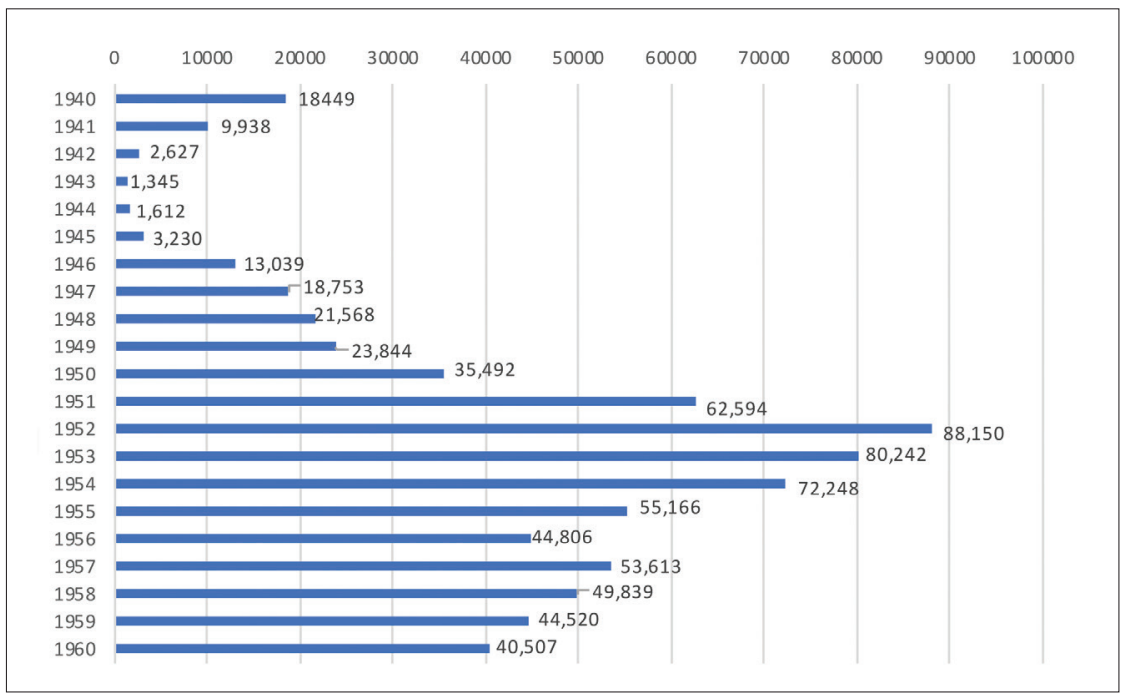

Fonte: Elaboração própria a partir de seleção de trecho da tabela "Imigração no Brasil 1820-1975”, publicada em VAINFAS, Ronaldo (Org.). Brasil: 500 anos de povoamento. IBGE, Centro de Documentação e Disseminação de Informações. Rio de Janeiro: IBGE, 2007, p. 225. Disponível em: <https://biblioteca.ibge.gov.br/visualizacao/livros/liv6687.pdf>. Acesso em: 10 mar. 2021.

Nas minas de carvão, a busca pela mão de obra europeia atingida pelo conflito mundial começou cedo. Já em dezembro de 1945, a direção do Cadem enviou carta ao então diretor da Divisão de Terras e Colonização do Ministério da Agricultura manifestando seu interesse em acolher 200 imigrantes de origem europeia, de preferência solteiros, para o serviço de mineração. A manifestação era uma resposta a um 
edital lançado pelo órgão federal relativo à imigração e elencava nacionalidades preferidas pela empresa: poloneses e lituanos, por "melhor se adaptarem aos serviços do subsolo das minas de carvão." ${ }^{14}$ Era oferecido, além dos salários (inicial de Cr\$22 diários, podendo chegar a Cr $\$ 40$ diários), residência e contrato pela CLT. ${ }^{15}$

Essa demanda por novos braços ocorria num contexto de crescente agitação operária nas minas. Nos primeiros meses de 1945, a exemplo do que se verificava em outros setores da economia brasileira, a mineração de carvão era palco de um recrudescimento de movimentos dos trabalhadores, animados pela redemocratização do Brasil com o fim da ditadura do Estado Novo e a consequente volta à legalidade do Partido Comunista (retorno que seria breve, pois em 1947 ele seria novamente colocado na ilegalidade). Assim, houve uma greve significativa nas minas no primeiro semestre de 1945, e outra, ainda mais forte, no ano seguinte. Essa paralisação, que se iniciou no dia da posse do novo presidente, general Eurico Gaspar Dutra, estendeu-se por dois meses, motivou uma série de enfrentamentos além da intervenção militar nas minas e provocou a demissão de dezenas de grevistas após seu término, em março de 1946 (SPERANZA, 2014).

Assim, não é surpreendente que, em nova carta, datada de 16 de agosto de 1946, e endereçada ao presidente do Conselho Nacional de Colonização e Imigração, a direção do Cadem reiterasse o pedido de 200 operários europeus. ${ }^{16} \mathrm{E}$ ainda no mesmo mês, a empresa chegou a entrar em contato direto com o General Marlewski, do setor de Emigração do Comitê Interino do Tesouro britânico para questões polonesas

14 ADMEC, Arroio dos Ratos. Fundo Consórcio Administrador de Empresas de Mineração (CADEM), Dossiê dos Imigrantes (Europeus), AHM, Ofício, 18 dez. 1945. Cx. 296. Em documento posterior, de 1947, a empresa citava como preferidos alemães, poloneses, ucranianos e russos brancos.

15 O salário mínimo mensal à época era de CR\$ 380 por mês. Portanto, a remuneração oferecida era superior.

16 ADMEC, Arroio dos Ratos. Fundo CADEM, Dossiê dos Imigrantes (Europeus). CARDOSO, Roberto. Carta para João Alberto Lins de Barros, presidente do Conselho Nacional de Colonização e Imigração, 16 ago. 1946. Cx. 296. 
(o Governo Provisório Polonês), solicitando operários poloneses para as minas brasileiras - pedido reiterado em janeiro de 1947.

Nesse segundo contato, os brasileiros salientaram que aceitavam (na verdade, preferiam) operários não especializados, para trabalhar como tocadores. Essa peculiaridade chama a atenção porque contradiz a política declarada do governo brasileiro de privilegiar técnicos qualificados entre os migrantes europeus. Na verdade, a categoria dos tocadores era uma das mais mal remuneradas entre os operários das minas, e demandava essencialmente força e resistência física. Sua função era basicamente empurrar os vagões com toneladas de carvão por quilômetros no subsolo. Era, porém, a parcela de trabalhadores mais numerosa do setor à época - porque não havia ainda tração elétrica para transporte da produção em toda a extensão do subsolo das minas. Ao contrário do ocorrido no início do século XX (SPERANZA, 2015), quando a demanda por trabalhadores europeus nas minas visava suprir a necessidade de operários com conhecimento do ofício e especializados (foi o caso de mineiros ingleses e posteriormente, dos espanhóis), ao fim da II Guerra Mundial, as empresas rio-grandenses já consideravam consolidados seus processos e buscavam preferencialmente operários não especializados dispostos a trabalhar nas funções mais duras do subsolo, provavelmente com o intuito de repor a alta e permanente rotatividade provocada pelo abandono, doenças, acidentes e aposentadorias precoces.

O segundo contato com o Governo Provisório Polonês parece ter tido mais sucesso, pois em fevereiro de 1947, Marlewski enviou carta informando que atenderia a demanda por 200 trabalhadores. Poucos meses depois, em abril de 1947, o Cadem enviou correspondência para o Conselho Nacional de Imigração e Colonização informando que a "falta de braços" e o "absenteísmo" dos operários provocavam a incapacidade das empresas em atender à demanda por carvão, dada a redução da produção. Na missiva, não era citada a redução da jornada de trabalho de oito para seis horas no subsolo das minas, definida pela Consolidação das Leis do Trabalho (CLT), de 1943, e a polêmica em torno do descanso semanal remunerado, previsto na nova Constituição de 1946, mas que as empresas recusavam-se a cumprir. 
A carta do Cadem ao Conselho Nacional de Imigração e Colonização ressaltava a importância do carvão mineral para a região, salientando que a produção abastecia a Viação Férrea, a navegação fluvial, lacustre e de cabotagem do Rio Grande do Sul, bem como o funcionamento de gás, luz, força e transportes públicos em três grandes cidades do estado (Pelotas, Rio Grande e Porto Alegre), a energia dos frigoríficos e de outras indústrias locais. ${ }^{17}$

Finalmente, em junho de 1947, o próprio ministro do Trabalho, Morvan Dias de Figueiredo, endereçou correspondência para as minas anunciando a chegada de 55 trabalhadores europeus, escolhidos de acordo com a autorização do ministério. ${ }^{18} \mathrm{Um}$ registro da Hospedaria dos Imigrantes arquivada no escritório das mineradoras indica a nacionalidade dos 55 operários recém-chegados: 33 ucranianos, 15 poloneses, 6 russos e um lituano. ${ }^{19}$ Com eles, vinham mais 69 mulheres e crianças. Um mês depois, outro documento da Hospedaria indicava mais 87 imigrantes para as minas, entre homens adultos e jovens, mulheres e crianças, com nacionalidades ucraniana, polonesa, húngara, alemã e tcheca, além de duas famílias apátridas. ${ }^{20}$ Já em dezembro de 1945, a direção do Cadem enviou carta ao então diretor da Divisão de Terras e Colonização do Ministério da Agricultura manifestando seu interesse em "acolher" 200 imigrantes de origem europeia, de preferência solteiros, para o serviço de mineração.

A documentação produzida pelo Consórcio Minerador referente à chegada desses e de outras levas de imigrantes nos anos posteriores

17 ADMEC, Arroio dos Ratos. Fundo CADEM, Dossiê dos Imigrantes (Europeus). Carta endereçada ao Conselho Nacional de Imigração e Colonização, 11 abr. 1947. Cx. 296.

18 ADMEC, Arroio dos Ratos. Fundo CADEM, Dossiê dos Imigrantes (Europeus). FIGUEIREDO, Morvan Dias de. Carta para Roberto Cardoso, 12 jun. 1947. Cx. 296.

19 ADMEC, Arroio dos Ratos. Fundo CADEM, Dossiê dos Imigrantes (Europeus). Relação de imigrantes alienígenas desta hospedaria, que se destinam as minas de "Butiá" no Estado do Rio Grande do Sul, 9 jun. 1947. Cx. 296.

20 ADMEC, Arroio dos Ratos. Fundo CADEM, Dossiê dos Imigrantes (Europeus). Relação de imigrantes alienígenas desta hospedaria, que se destinam as minas de "Butiá" no Estado do Rio Grande do Sul, 2 jul. 1947. Cx. 296. 
mostra detalhadamente as informações consideradas essenciais pelas empresas e um controle estrito e quase individual dos imigrantes. Eram relatados nome, idade, ocupação, nacionalidade e estado civil de cada operário "chefe de família", nome, nacionalidade, profissão e idade da mulher se casados, nome, idade e profissão dos filhos. Uma análise dessas listas permite observar traços do perfil das famílias que vinham trabalhar no subsolo das minas de carvão brasileiras vindas da Europa no imediato pós-guerra.

As ocupações masculinas listadas são "operário" ou "trabalhador" (imensa maioria), "técnico de minas" ou "mineiro", "eletricista" ou "montador elétrico", "químico", "carpinteiro", "marceneiro", "laminador" e "telegrafista". As mulheres aparecem, quase invariavelmente, como "domésticas" (donas de casa). Em apenas dois casos, a mulher consta como "costureira", e noutro uma moça de 21 anos, ucraniana, aparece como arquiteta-desenhista. Não sabemos se suas trajetórias posteriores no Brasil, porém vale lembrar que nas minas de carvão do Rio Grande do Sul (ao contrário das de Santa Catarina) não há registro de utilização da mão de obra feminina na produção do minério. ${ }^{21}$

Em levantamento nessa documentação, conseguimos identificar 230 nomes de migrantes encaminhados para as minas de carvão nos anos de 1947 e 1948 com suas famílias. As nacionalidades incluíam poloneses, poloneses/ucranianos, alemães, húngaros, romenos, iugoslavos, letões, russos, lituanos e tchecos - ou seja, com vasta predominância de populações do Leste europeu. Outros 89 aparecem com nacionalidade desconhecida, e incluem aparentemente tanto estrangeiros quanto brasileiros vindos de outros estados, em especial Minas Gerais.

Apesar da preferência da empresa por trabalhadores solteiros, a maioria que teve informado seu estado civil (82) era casada, contra 67 solteiros, e 81 com estado civil “desconhecido". Em 54 casos, há registro de filhos e/ou outros membros familiares além da esposa. Os imigrantes

21 Sobre o papel das mulheres nas minas do Rio Grande do Sul, ver SPERANZA, 2020-2021. A respeito do trabalho nas minas de Santa Catarina exercido por mulheres, ver MANDELLI, 2020; CAROLA, 2002. 
mais novos, na casa dos 20 anos, geralmente migravam sozinhos, ao contrário dos mais velhos. Mas o recém-chegado mais idoso, o lituano João Furmanis (o prenome provavelmente foi aportuguesado no registro), de 53 anos, imigrou sozinho, apesar de ser casado. Ele começou a trabalhar em junho de 1947, mas deixou as minas pouco mais de um ano depois, em setembro de 1948. Como Furmanis, outros 74 trabalhadores recém-chegados abandonaram as minas no curto intervalo desses dois anos.

\section{“GENTE NOVA” E REVOLTA SOCIAL}

Além dos esforços das mineradoras para "importar" mão de obra através de contatos com órgãos governamentais nacionais e europeus, havia também casos de trabalhadores que escreviam se oferecendo para trabalhar. Um grupo de moradores da Alemanha sob ocupação britânica enviou carta ao Cadem em 17 de janeiro de 1947, com o apelo: "Somos gente nova, 23, 25 e 26 anos de idade e de profissão mecânicos e construtores de máquinas. Sem nos deixar levar por ilusões, temos unicamente o desejo de trabalhar e obter em troca os meios de subsistência".22

A resposta, de fato, não alimentava ilusões. Na correspondência enviada do Brasil para os operários, a empresa manifestou interesse nos trabalhadores, mas fez notar sua inclinação para trabalhadores que se dispusessem a exercer a função de tocador, descrita como atividade na qual os operários “apanham o carvão do chão, com pás, e o colocam em vagonetes, empurrando-as sobre trilhos, até o lugar onde serão transportados mecanicamente", sendo que "uma vagoneta, quando cheia com carvão, pesa cerca de 800 quilos". 23

O controle sobre os imigrantes envolvia uma avaliação constante sobre suas capacidades e atitudes, que se iniciava já nos primeiros meses

22 ADMEC, Arroio dos Ratos. Fundo CADEM, Dossiê dos Imigrantes (Europeus). Carta enviada por Guneld Schuemann Elmshorn à direção das minas, 17 jan. 1947. Cx. 296.

23 ADMEC, Arroio dos Ratos. Fundo CADEM, Dossiê dos Imigrantes (Europeus). Correspondência endereçada a Guneld Schuemann pela direção do Cadem, 7 abr. 1947. Cx. 296. 
nas minas. Em carta datada de dezembro de 1948, o engenheiro-chefe das minas relatava ao engenheiro assistente da direção do Cadem que era feita uma divisão entre "bons", "regulares" e "maus" operários. E informava os critérios para essa avaliação: "classificamos como maus operários elementos que vivem reclamando das condições do serviço, dão pouca produção e procuram, sempre, transferências para tarefas mais leves que as do subsolo". A subserviência e a obediência eram, portanto, requisitos para ser bem avaliado. Porém, ser classificado como bom operário dava poucas garantias ao trabalhador no cotidiano da produção, conforme o mesmo ofício: "não podemos garantir que esses homens permaneçam nestas categorias. Amanhã ou depois poderemos precisar despedir mesmo um bom operário que se mostrar desidioso ou faltoso". ${ }^{24}$

A documentação administrativa mostra ainda que o processo de controle patronal nas minas ia muito além da classificação em "bons" e "maus" operários, e confirma o período de tensão política nas vilas mineiras no período. Uma lista com 54 nomes intitulada "lista dos comunistas das minas do Butiá" inclui mineiros da ativa, aposentados e até trabalhadores da Estrada de Ferro do Jacuí, da Viação Férrea Estadual, que não pertencia à mineradora, mas cruzava a mina. Essa vigilância sobre os trabalhadores incluía redes formais (polícia, exército), mas também informais. Qualquer comportamento considerado politicamente perigoso era imediatamente monitorado e comunicado à polícia.

Em julho de 1947, por exemplo, a direção das minas enviou ofício ao então Chefe de Polícia do estado queixando-se que 16 de um grupo de 50 trabalhadores europeus enviados à vila de Butiá "negam-se peremptoriamente, insuflados por elementos existentes nas minas, a entrar em serviço". ${ }^{25} \mathrm{O}$ fato ensejaria a ida às minas do representante

24 ADMEC, Arroio dos Ratos. Fundo CADEM, Dossiê dos Imigrantes (Europeus). Carta do Engenheiro Chefe (nome não legível) a Genésio da Costa Marques, Engenheiro Assistente do Diretor da CADEM, 22 dez. 1948. Cx. 296.

25 ADMEC, Arroio dos Ratos. Fundo CADEM. Carta da direção das minas ao Chefe de Polícia do RS, 3 jul. 1947. 
no Brasil do Comitê Intergovernamental de Refugiados da Inglaterra, órgão que havia financiado a passagem dos trabalhadores. No mês seguinte, em carta particular endereçada ao engenheiro-chefe das Minas do Butiá, outro engenheiro da empresa comunicava o acordo feito com o delegado de polícia local para o afastamento de "seis elementos polacos aí radicados, que têm perturbado a fixação dos imigrantes que ultimamente recebemos" ${ }^{26}$

Por outro lado, em contraste com os trabalhadores que abandonavam a mina, outros eram rejeitados pela própria mineradora. Em 20 de setembro de 1948, por exemplo, um memorando interno indicava a rejeição de dois operários alemães e seu encaminhamento de retorno para a Ilha das Flores (onde se localizava a Hospedaria dos Imigrantes) "em virtude da avançada idade". ${ }^{27} \mathrm{~A}$ indicação pelas mineradoras, nas correspondências, que as despesas de retorno caso o operário e sua família não se adaptassem às minas correriam por conta do governo demonstra que tal fato era comum.

Uma lista intitulada "Relação dos operários imigrantes que desejam abandonar Butiá", datada de 16 de janeiro de 1948, ${ }^{28}$ indica algumas das razões para a saída massiva dos recém-chegados após o contrato inicial de seis meses. O documento, com o nome de 32 trabalhadores, informa as razões para as quais eles pretendiam deixar as minas, para onde tencionavam ir e quais as profissões (nacionalidades não são informadas). Dos 32 nomes, apenas 6 informavam para onde pretendiam migrar (quatro para Porto Alegre e dois para São Paulo). Importante notar que a moradia na vila (em casas de propriedade da companhia) estava atrelada ao trabalho - portanto, ao deixar o emprego, os trabalhadores também abdicavam das casas. As razões alegadas para as saídas

26 ADMEC, Arroio dos Ratos. Documentos CADEM 1946-1948. Ofício, 27 ago. 1947.

27 ADMEC, Arroio dos Ratos. Fundo CADEM, Dossiê dos Imigrantes (Europeus). Memorando 250/48, 20 set. 1948. Cx. 296.

28 ADMEC, Arroio dos Ratos. Fundo CADEM, Dossiê dos Imigrantes (Europeus). Relação dos operários imigrantes que desejam abandonar "Butiá", 16 jan. 1948. Cx. 296. 
são variadas, mas predominam o fim do contrato inicial de seis meses, falta de saúde para trabalhar nas minas, o fato de o serviço ser perigoso ou pesado, e considerar o salário baixo.

Apesar de limitado, o levantamento dessa documentação revela, além do fluxo de imigrantes e suas origens principais (bem como do interesse das mineradoras em atrair um número significativo de trabalhadores), as resistências dessas famílias à exploração intensiva do trabalho verificada no subsolo das minas. Embora com poucas perspectivas e escolhas diante das condições resultantes da tragédia da guerra, um número significativo desses operários preferiu deixar as minas (onde tinha salário, casa e lazer) devido às péssimas condições de trabalho e à grande periculosidade.

Um incidente ocorrido no final de 1949, e documentado em processo judicial trabalhista do início de 1950, dá pistas tanto sobre o processo de aliciamento de mão de obra quanto da forma como que os trabalhadores faziam conhecer aos recém-chegados sobre os direitos trabalhistas. ${ }^{29} \mathrm{O}$ processo, movido por João de Deus de Castro, mineiro da Companhia Carbonífera Minas do Butiá, relata um enfrentamento ocasionado pela chegada de uma leva de novos operários às minas, não do exterior, mas da vizinha cidade de Camaquã. O trabalhador teria tentando intimidar os novos mineiros, que estavam em vias de assinar suas entradas na seção de pessoal; conforme a companhia, teria dito aos novatos "que o operário que assinasse o compromisso para trabalhar horas-extras apanharia”. Previsivelmente, Castro foi em seguida demitido, o que o motivou a procurar a Justiça. A situação narrada no processo por ele coincide em termos gerais à descrita pelos representantes patronais, mas o operário acrescenta que os componentes do grupo de novos empregados haviam lhe perguntado qual era o horário de trabalho no subsolo. Os recém-chegados queriam saber "se os

29 ARQUIVO DO MEMORIAL DA JUSTIÇA DO TRABALHO (AMJT), Porto Alegre. Junta de Conciliação e Julgamento de São Jerônimo. Processo 07/52 Audiência de 11 jan. 1952, 1952. Livro de atas de audiência da Junta de Conciliação e Julgamento de São Jerônimo, 1952. 
empregados do subsolo estavam obrigados a trabalharem as oito horas, ao que o declarante respondeu que não, pois o horário do subsolo era de 6 horas". ${ }^{30}$ E Castro aconselhou aos novos que "não deveriam assinar o compromisso de trabalharem as 8 horas, pois do contrário apanhariam dos outros".

Além de indicar a forma incisiva pela qual os trabalhadores lutavam por seus direitos (o que incluía a coesão física sobre os próprios colegas recalcitrantes), o incidente pode ser uma pista de como as empresas mineradoras burlavam as leis trabalhistas - a limitação da jornada de 6 horas dos operários do subsolo das minas prevista na CLT por meio de novos contratados, que desconheciam a legislação. Nesse episódio, os novos trabalhadores vinham de um município vizinho, mas assim como eles, os imigrantes estavam sujeitos às mesmas condições de trabalho e aos mesmos mecanismos de burla dos direitos trabalhistas.

\section{CONSIDERAÇÕES FINAIS}

A II Guerra Mundial trouxe transformações intensas para a humanidade, em especial para o mundo do trabalho. Destruição e morte conviveram, paradoxalmente (como é comum nos conflitos bélicos) com novas tecnologias, migrações, mudanças geopolíticas e institucionais, transformações de valores sociais. No Brasil, a mobilização de guerra produziu, entre outras consequências, a identificação do trabalho manual com a defesa nacional, uma estratégia de mobilização dos trabalhadores e trabalhadoras que ocorria em paralelo com a suspensão dos direitos trabalhistas recém conquistados, em especial pela promulgação da CLT, de 1943. Fortes e Ribeiro salientam que

30 A limitação da jornada de trabalho em seis horas diárias no subsolo das minas fora implantada pela Consolidação das Leis do Trabalho (CLT), em 1943 (artigo 293), apenas seis anos antes do incidente. BRASIL. Consolidação das Leis do Trabalho. Decreto-lei no 5.452, de 1 maio 1943. Art. 293. A duração normal do trabalho efetivo para os empregados em minas no subsolo não excederá de 6 (seis) horas diárias ou de 36 (trinta e seis) semanais. Diário Oficial da União, Rio de Janeiro, 1943. 
como efeito colateral gerado pela mobilização patriótica em prol da guerra contra o Eixo, a classe trabalhadora assumiu um destacado protagonismo político no país a partir de 1945, lutando tanto pela garantia de direitos sociais quanto pela conquista de novas reivindicações. (FORTES; RIBEIRO, 2019, p. 16)

O processo de redemocratização pós-Estado Novo foi marcado, assim, por um aumento destacado das mobilizações dos trabalhadores brasileiros, interrompidas durante a ditadura getulista. Essa ampliação ocorre a partir mesmo de 1945, com uma série de greves ainda na vigência do regime autoritário (FRENCH, 1995; KONRAD, 2006; SOUZA, 2019) e, posteriormente, com o ciclo de mobilizações do início de 1946, tendo inicialmente o protagonismo do recém-criado Movimento Unificador dos Trabalhadores (MUT), ligado ao PCB. ${ }^{31}$

A criação do PTB ainda em 1945 abriu um novo flanco de enfrentamento dos operários com o patronato, agora sob a bandeira da legalidade, da ênfase no papel apaziguador da Justiça do Trabalho e da negociação. Na prática, porém, muitos líderes sindicais ligados ao PTB agiram em suas bases defendendo greves ou mobilizações nos locais de trabalho, inclusive para fazer frente à mobilização dos comunistas nas bases. E também a Justiça do Trabalho se revelou na prática mais uma arena adicional (e importantíssima) de confrontação do que uma instância de apaziguamento das relações de trabalho. ${ }^{32}$

Se a formação da classe é um processo cultural no qual as tradições, reais ou inventadas, têm papel crucial, é possível pensar que o patronato naquele momento tenha visto na oferta de trabalhadores europeus refugiados ou "deslocados de guerra" a mesma "oportunidade" que os fazendeiros de café paulistanos ao fim do século XIX.

31 Sobre a fundação do MUT e da posterior Confederação Geral dos Trabalhadores do Brasil (CGBT), ver SILVA; SANTANA, 2007; COSTA, 1995; SILVA; NEGRO, 2003.

32 Saliento aqui que o papel apaziguador da Justiça do Trabalho era um projeto político defendido pelo PTB (não sem contradições), o que não significa que tenha se realizado na prática. Pelo contrário, como mostra a recente historiografia. Ver, por exemplo, GOMES; SILVA, 2013; SILVA, 2016 e a minha própria pesquisa, SPERANZA, 2014. 
Recentemente, pesquisadores ressaltaram que o incentivo à imigração e à substituição da mão de obra escravizada teve, além da motivação do "branqueamento" da nação, o plano de criar uma oferta ampla de mão de obra capaz de manter as remunerações pagas em níveis muito baixos, aumentando a competitividade entre os trabalhadores e desestimulando solidariedades e movimentos coletivos (HALL, 2003; BATALHA, 2014).

A mesma estratégia pode estar presente no pós II Guerra Mundial, pelo menos entre alguns setores, como indica o caso dos mineiros de carvão. As razões expostas por esse patronato para solicitar o envio de novos trabalhadores ao Comitê de Refugiados são extremamente questionáveis. Embora alegassem falta de mão de obra e absenteísmo, as empresas mineradoras de carvão do RS oficiaram pela Justiça do Trabalho o desligamento de 3.321 trabalhadores de 1946 a 1954, 97\% desses trabalhadores não-estáveis (empregados há menos de 10 anos). Isso representa cerca de $40 \%$ do total da força de trabalho empregada das minas em $1943 .{ }^{33}$ Parte desse total certamente se deu por abandono de emprego, mas há evidências que ocorreram demissões em número considerável, o que é contraditório com o argumento de escassez de força de trabalho. As demissões aqui têm como principais alvos, aparentemente, a mobilização coletiva e a memória da conquista e, principalmente, da vigência legal dos direitos trabalhistas (os "direitos sociais") previstos na CLT.

Além disso, o fato de serem demandados especialmente trabalhadores não especializados (para suprir a função de tocadores) é mais uma evidência de que os empresários tinham na prática objetivos diversos do que o projeto governamental e diplomático brasileiro defendia oficialmente, que era, relembramos, privilegiar a vinda de agricultores e mão de obra especializada. O que os patrões queriam (pelo menos nas minas de carvão), ao contrário, eram trabalhadores não qualificados, a fim de ampliar a reserva da força de trabalho, alimentando a competição entre os operários, o que costuma ser uma estratégia eficaz para enfraquecimento do movimento sindical.

33 De 1946 a 1954, foram oficializadas nas minas do Rio Grande do Sul as demissões de 3.321 trabalhadores, $97 \%$ destes não-estáveis, o que representa cerca de $40 \%$ do total da força de trabalho empregada das minas em 1943, conforme SPERANZA, 2014. 
Tal hipótese se alicerça no exame do caso concreto em questão, que tem alcance limitado às minas de carvão. Novas pesquisas em outros setores específicos, a partir da documentação empresarial (entre outras) poderiam comprová-la ou não. Porém, a partir do que foi aqui levantado, podemos supor que o estímulo permanente à existência de uma significativa mão de obra de reserva foi instrumento recorrente da luta de classes no Brasil. Poderíamos acrescentar ao contexto da substituição do trabalho escravizado por livre, na transição do século XIX e $\mathrm{XX}$, o contínuo e volumoso fluxo de escravizados verificado ao longo do século XIX, em especial após as revoltas escravas da terceira década. ${ }^{34}$ Colocada em termos atuais, a oferta excessiva de braços no mercado de trabalho foi utilizada em vários momentos históricos como estímulo à precarização e, em contraponto, desestímulo ao movimento operário. Que esse mesmo movimento tenha conseguido, nesse contexto, organizar-se e protagonizar mobilizações importantes, demonstra sua enorme capacidade de reinventar-se e sobreviver na terra de Vera Cruz.

\section{Agradecimentos}

A autora agradece ao pesquisador estadunidense Cody Williams, que repassou a esta pesquisa cópias digitais da documentação do Museu Estadual do Carvão do Rio Grande do Sul referente ao período 1946-1948 (Dossiê Imigrantes). A compilação quantitativa da documentação foi feita pelo bolsista de iniciação científica Guilherme Giotti Sichelero, a quem também agradeço.

34 Conforme o projeto Slave Voyages, da Emory University, que armazena e disponibiliza o tráfico transatlântico de escravizados entre 1501 e 1866, do total de 5,8 milhões de pessoas negras embarcadas na África com destino ao Brasil nesse intervalo de tempo, quase 1 milhão (855.882) se refere ao período posterior a 1835, ano da Revolta dos Malês, em Salvador. Conforme Reis (2003), a revolta marcou um aumento da preocupação no controle da mão de obra escravizada no Brasil, inclusive com a edição da lei de 10 de junho de 1835, que estabelecia pena de morte para os escravos que assassinassem ou ferissem gravemente senhores, feitores, administradores ou membros das famílias com quem morassem. Os dados do projeto Slave Voyages estão disponíveis em: $<$ https://www.slavevoyages.org/ $>$. 


\section{REFERÊNCIAS BIBLIOGRÁFICAS}

ANDRADE, José H. Fischel de. O Brasil e a organização internacional para os refugiados (1946-1952). Revista Brasileira de Política Internacional, v. 48, n. 1, p. 60-96, jun. 2005.

BAENINGER, Rosana; SALLES, Maria do Rosário Rolfsen. Apresentação. In: SALLES, Maria do Rosário Rolfsen et al (Org.). Imigrantes internacionais no pós-Segunda Guerra Mundial. Campinas: Núcleo de Estudos de População - Nepo/Universidade Estadual de Campinas, Faculdade Anhembi Morumbi, Universidade Federal de São Paulo, 2013. p. 7-9.

BASTOS, Sênia; SALLES, Maria do Rosário Rolfsen. A Imigração polonesa para São Paulo no pós-Segunda Guerra Mundial no quadro das entradas dos "deslocados de guerra": 1947 a 1951. Revista Brasileira de Estudos Populacionais, v. 31, n. 1, p. 151-167, jan.-jun. 2014.

BATALHA, Claudio. Formação da classe operária e projetos de identidade coletiva. In: FERREIRA, Jorge; DELGADO, Lucília de Almeida Neves (Org.). O Brasil republicano. O tempo do liberalismo excludente, da proclamação da república à revolução de 1930. Rio de Janeiro: Civilização Brasileira, 2014. p. 161-189.

BRAVO, André Luiz Morais Zuzarte. O Milhão restante, o Brasil e a evolução da proteção internacional a refugiados (1946-1952). Dissertação (Mestrado em História, Política e Bens culturais) - Centro de Pesquisa e Documentação de História Contemporânea do Brasil/Fundação Getúlio Vargas, Rio de Janeiro, 2014.

CAROLA, Carlos Renato. Dos Subterrâneos da História: as trabalhadoras das minas de carvão de Santa Catarina (1937-1964). Florianópolis: UFSC, 2002.

COSTA, Hélio da. Em Busca da memória: comissão de fábrica, partido e sindicato no pós-guerra. São Paulo: Scritta, 1995.

DISSÍDIO COLETIVO. Sindicato dos Trabalhadores na Indústria da Extração do Carvão. Porto Alegre: Livraria do Globo, 1943.

FERREIRA, Jorge. A Redemocratização e o movimento queremista. In: FERREIRA, Jorge; DELGADO, Lucília de Almeida Neves (Org.). 
História do Brasil Republicano 3. O tempo da experiência democrática - da democratização de 1945 ao golpe civil-militar de 1964. Rio de Janeiro: Civilização Brasileira, 2003. p. 15-46.

FORTES, Alexandre; RIBEIRO, Felipe. Trabalhadores e Segunda Guerra Mundial: debates introdutórios para um dossiê. Revista Mundos do Trabalho, v. 11, p. 1-17, out. 2019.

FRENCH, John. $O A B C$ dos operários: conflitos e alianças de classe em São Paulo, 1900-1950. São Paulo/São Caetano do Sul: Hucitec/Prefeitura de São Caetano do Sul, 1995.

FREYRE, Gilberto. Casa Grande e Senzala. São Paulo: Global, 2006.

GERALDO, Endrica. A "lei de cotas" de 1934: controle de estrangeiros no Brasil. Cadernos AEL, v. 15, n. 27, p. 174-209, mar. 2009.

GOMES, Angela de Castro (Coord.). Ministério do Trabalho: uma história vivida e contada. Rio de Janeiro: CPDOC, 2007.

GOMES, Angela de Castro; SILVA, Fernando Teixeira da (Org.). A Justiça do Trabalho e sua história. Campinas: Unicamp, 2013.

HALL, Michael. Os Fazendeiros paulistas e a imigração. In: SILVA, Fernando Teixeira; NAXARA, Márcia R. Capelari; CAMILOTTI, Virgínia (Org.). República, liberalismo, cidadania. Piracicaba: Unimep, 2003. p. 153-161. KONRAD, Glaucia. Os Trabalhadores e o Estado Novo no Rio Grande do Sul: um retrato da sociedade e do mundo do trabalho (1937-1945). Tese (Doutorado em História) -Universidade Estadual de Campinas, Campinas, 2006.

MANDELLI, Bruno. Das Minas de carvão para a Justiça: as lutas dos mineiros acidentados em Criciúma (SC). Jundiaí: Paco, 2020.

MATTOS, Marcelo Badaró. Trabalhadores e sindicatos no Brasil. São Paulo: Expressão Popular, 2009.

REIS, João José. Rebelião escrava no Brasil: a história do levante dos malês em 1835. São Paulo: Companhia das Letras, 2003.

REVISTA de Imigração e Colonização, Rio de Janeiro, v. 9, n. 1, mar. 1948. SALLES, Maria do Rosário R. Imigração e política imigratória brasileira no pós-Segunda Guerra Mundial. Cadernos CERU, v. 2, n. 13, p. 100-101, 2002. 
SALLES, Maria do Rosário R. A Política imigratória brasileira no pós-Segunda Guerra Mundial e os refugiados: uma leitura da Revista de Imigração e Colonização. Revista Cena Internacional, v. 9, n. 2, p. 184-210, 2007.

SILVA, Fernando Teixeira. Trabalhadores no tribunal: conflitos e justiça do trabalho em São Paulo no contexto do Golpe de 1964. São Paulo: Alameda, 2016.

SILVA, Fernando T. da; NEGRO, Antonio Luigi. Trabalhadores, sindicatos e política (1945-1964). In: FERREIRA, Jorge; DELGADO, Lucília de Almeida Neves. O Brasil republicano. O tempo da experiência democrática, da democratização de 1945 ao golpe civil-militar de 1964, v. 3. Rio de Janeiro: Civilização Brasileira, 2003. p. 155-194.

SILVA, Fernando T. da; SANTANA, Marco Aurélio. O Equilibrista e a política: o "Partido da Classe Operária" (PCB) na democratização (1945-1964). In: FERREIRA, Jorge; REIS, Daniel Aarão. As Esquerdas no Brasil: nacionalismo e reformismo radical (1945-1964). Rio de Janeiro: Civilização Brasileira, 2007. p. 101-140.

SOUZA, Edinaldo Antonio Oliveira de. Trabalhadores, sindicatos e lutas por direitos na Bahia no final da Segunda Guerra Mundial. Revista Mundos do Trabalho, v. 11, p. 1-26, dez. 2019.

SOUZA, Rafael de Freitas. Trabalho e cotidiano na mineração aurífera inglesa em Minas Gerais: a Mina da Passagem em Mariana (1863-1927). Tese (Doutorado em História) - Universidade de São Paulo, São Paulo, 2009.

SPERANZA, Clarice G. Cavando direitos: as leis trabalhistas e os conflitos entre os mineiros de carvão e seus patrões no Rio Grande do Sul (1940-1954). São Leopoldo: Oikos, Porto Alegre: ANPUHRS, 2014.

SPERANZA, Clarice G. European workers in Brazilian coalmining, 1850-1950. International Review of Social History, v. 60, n. 1, p. 165-183, Feb. 2015.

SPERANZA, Clarice G. Gênero e classe numa comunidade de mineração de carvão do Brasil em meados do século XX. Revista Latinoamericana de Trabajo y Trabajadores, v.1, p. 113-136, nov. 2020-abr. 2021. 
VAINFAS, Ronaldo (Org.). Brasil: 500 anos de povoamento. Rio de Janeiro: IBGE, 2007. Disponível em: <https://biblioteca.ibge.gov.br/visualizacao/ livros/liv6687.pdf>. Acesso em: 10 mar. 2021.

WOODRUM, Robert. Everybody was Black down there: Race and Industrial Change in the Alabama Coalfields. Georgia: Press University, 2007. 